\title{
Aminolysis of 2,4-Dinitrophenyl and 3,4-Dinitrophenyl Diphenylphosphinothioates: Steric Hindrance versus Nucleofugality in Nucleophilic Substitution Reactions
}

\author{
Li-Ra Im, Ji-Sook Min, ${ }^{a}$ Kalsoom Akhtar, and Ik-Hwan Um ${ }^{*}$ \\ Department of Chemistry and Nano Science, Ewha Womans University, Seoul 120-750, Korea. *E-mail: ihum@ewha.ac.kr \\ Received April 15, 2011, Accepted May 4, 2011
}

Key Words : Aminolysis, Steric hindrance, Nucleofugality, Reaction mechanism, Brønsted-type plot

\begin{abstract}
Aminolyses of esters have been reported to proceed through a concerted mechanism or through a stepwise pathway with one or two intermediates (i.e., a zwitterionic tetrahedral intermediate $\mathrm{T}^{ \pm}$and its deprotonated form $\mathrm{T}^{-}$) depending on the nature of the electrophilic centers (e.g., $\mathrm{C}=\mathrm{O}, \mathrm{C}=\mathrm{S}, \mathrm{P}=\mathrm{O}$ and $\mathrm{P}=\mathrm{S}){ }^{1-12}$ Reactions of carboxylic esters $(\mathrm{C}=\mathrm{O})$ with amines have generally been reported to proceed through a stepwise mechanism. The rate-determining step (RDS) has been suggested to be dependent on the basicity of the incoming amine and the leaving group, i.e., it changes from breakdown of $\mathrm{T}^{ \pm}$to it formation as the incoming amine becomes more basic than the leaving group by 4 to $5 \mathrm{p} K_{\mathrm{a}}$ units on the basis of a curved Brønsted-type plot found for aminolysis of esters possessing a good leaving group such as 2,4- or 3,4-dinitrophenoxide. ${ }^{1-10}$ In contrast, aminolysis of thiono esters $(\mathrm{C}=\mathrm{S})$ has been shown to proceed through two intermediates (i.e., $\mathrm{T}^{ \pm}$and $\mathrm{T}^{-}$), ${ }^{11}$ while the corresponding reactions of phosphorus esters $(\mathrm{P}=\mathrm{O}$ and $\mathrm{P}=\mathrm{S})$ proceed through a concerted mechanism. ${ }^{12}$

It is well known that nucleofugality of a given family of leaving groups increases as the leaving-group basicity decreases. However, Gresser and Jencks have found that 2,4dinitrophenyl acetate (1a) is less reactive than 3,4-dinitrophenyl acetate (1b) although 2,4-dinitrophenoxide in $\mathbf{1 a}$ is less basic than 3,4-dinitrophenoxide in $\mathbf{1 b}$ by $1.3 \mathrm{p} K_{\mathrm{a}}$ units. $^{9 \mathrm{a}}$ A similar result has been reported for quinuclidinolysis of 2,4-dinitrophenyl phenyl carbonate (2a) and 3,4-dinitrophenyl phenyl carbonate $(\mathbf{2 b}) .{ }^{9 \mathrm{~b}}$ Steric hindrance exerted by 2- $\mathrm{NO}_{2}$ group in $\mathbf{1 a}$ and $\mathbf{2 a}$ has been suggested to be responsible for the unexpected reactivity order. ${ }^{9}$
\end{abstract}

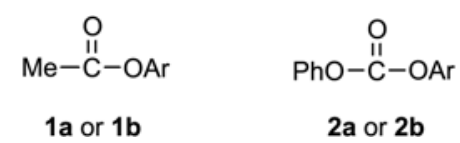

We have recently shown that 2,4-dinitrophenyl benzoate (3a), 2-furoate (4a) and 2-thiophenecarboxylate (5a) are more reactive than 3,4-dinitrophenyl benzoate (3b), 2furoate (4b) and 2-thiophenecarboxylate $(\mathbf{5 b})$, respectively, toward weakly basic amines (e.g., $\left.\mathrm{p} K_{\mathrm{a}}<10\right)$ but less reactive toward strongly basic amines (e.g., piperidine and 3-methylpiperidine). ${ }^{10}$ Dissection of the second-order rate constant $\left(k_{\mathrm{N}}\right)$ into the microscopic rate constants $k_{1}$ and $k_{2} / k_{-1}$ ratio has

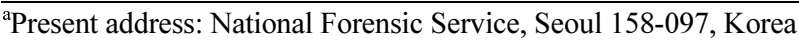

revealed that substrates possessing less basic 2,4-dinitrophenoxide (e.g., 3a, 4a and 5a) exhibit smaller $k_{1}$ values but larger $k_{2} / k_{-1}$ ratios than those bearing more basic 3,4-dinitrophenoxide (e.g., $\mathbf{3 b}, \mathbf{4 b}$ and $\mathbf{5 b}){ }^{10}$<smiles>COCCOCCOC(=O)c1ccccc1</smiles><smiles>O=C(O[Ga])c1ccco1</smiles><smiles></smiles>

We have extended our study to reactions of 2,4-dinitrophenyl and 3,4-dinitrophenyl diphenylphosphinothioates (e.g., 6a and 6b, respectively) with 7 different alicyclic secondary amines (Scheme 1) to investigate the effect of 2$\mathrm{NO}_{2}$ group on reactivity. We wish to report that the high nucleofugality of 2,4-dinitrophenoxide outweighs the steric hindrance that might be exerted by $2-\mathrm{NO}_{2}$ group in the aminolysis of $6 \mathbf{a}$ and $\mathbf{6 b}$.

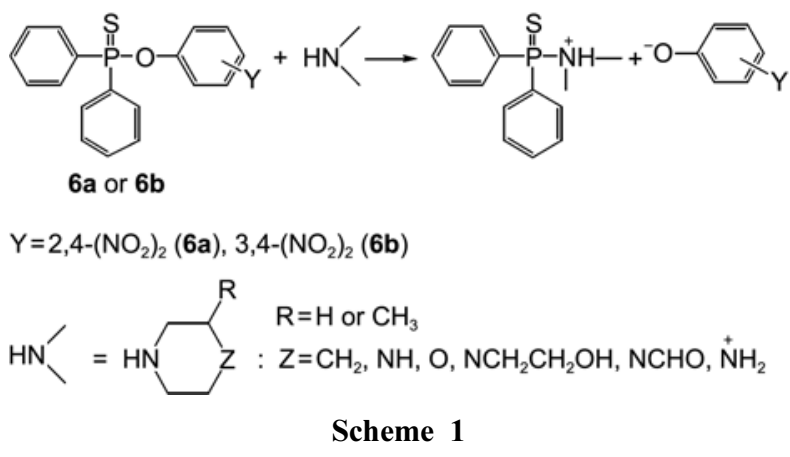

Results and Discussion

The kinetic study was performed under pseudo-first-order conditions in which the amine concentration was kept in excess over the substrate concentration. The reactions obeyed first-order kinetics and pseudo-first-order rate constants $\left(k_{\text {obsd }}\right)$ were calculated from the equation, $\ln \left(A_{\infty}-A_{\mathrm{t}}\right)=$ $-k_{\text {obsd }} t+C$. As shown in Figure 1, plots of $k_{\text {obsd }} v s$. amine concentrations are linear and pass through the origin, indicating that general base catalysis by a second amine molecule is absent and contribution of $\mathrm{H}_{2} \mathrm{O}$ and/or $\mathrm{OH}^{-}$from hydrolysis of amines to $k_{\text {obsd }}$ is negligible. Thus, the secondorder rate constants $\left(k_{\mathrm{N}}\right)$ were calculated from the slope of the linear plots. Based on replicate runs, it is estimated that the uncertainty in the $k_{\mathrm{N}}$ values is less than $\pm 3 \%$. The $k_{\mathrm{N}}$ 


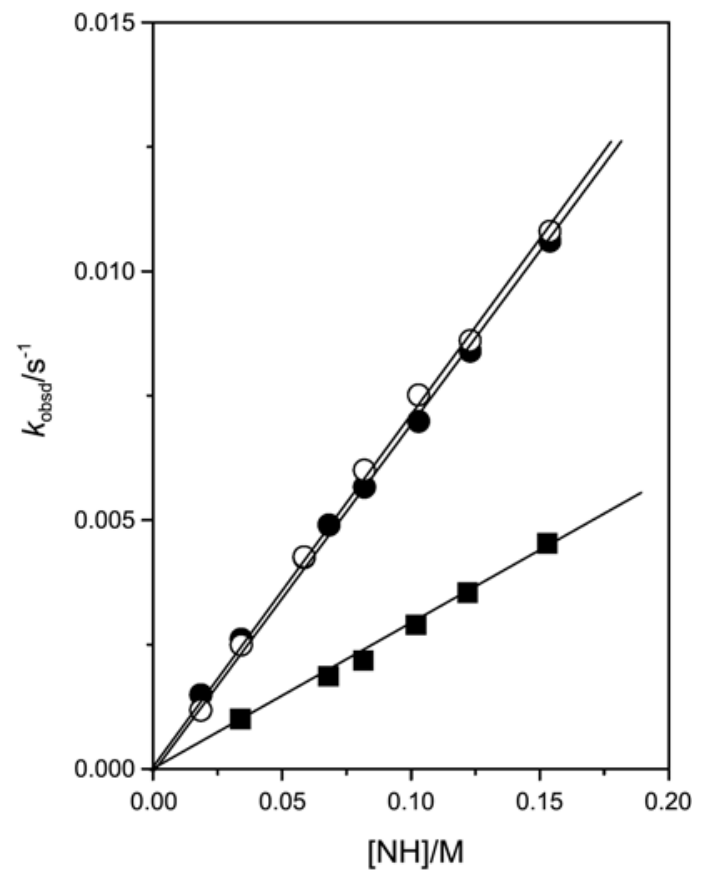

Figure 1. Plots of $k_{\text {obsd }} v s$. amine concentrations for the reactions of 3,4-dinitrophenyl diphenylphosphinothioate $(\mathbf{6 b})$ with piperidine $(\bullet)$, 3-methylpiperidine ( $\mathrm{O}$ ), and piperazine ( $(\boldsymbol{a})$ in $80 \mathrm{~mol} \% \mathrm{H}_{2} \mathrm{O} / 20$ $\mathrm{mol} \% \mathrm{DMSO}$ at $25.0 \pm 0.1{ }^{\circ} \mathrm{C}$

values calculated in this way are summarized in Table 1 for the reactions of $\mathbf{6 b}$ with 7 different amines together with those reported previously for the corresponding reactions of $\mathbf{6 a}$ for comparison.

Effect of 2-Nitro Group on Reactivity. Table 1 shows that $\mathbf{6 a}$ is more reactive than $\mathbf{6 b}$ regardless of amine basicity. This is consistent with the expectation that 2,4-dinitrophenoxide is a better nucleofuge than 3,4-dinitrophenoxide, but contrasts to the reports that carboxylic esters possessing 2,4dinitrophenoxide as a leaving group (e.g., 3a, 4a and 5a) are less reactive than those bearing 3,4-dinitrophenoxide (e.g., $\mathbf{3 b}, \mathbf{4 b}$ and $\mathbf{5 b}$ ) toward strongly basic amines (e.g., piperidine and 3-methylpiperidine). ${ }^{10}$

Aminolyses of 3, $\mathbf{4}$ and $\mathbf{5}$ have been reported to proceed

Table 1. Summary of second-order rate constants $\left(k_{\mathrm{N}}\right)$ for reactions of 2,4-dinitrophenyl diphenylphosphinothioate (6a) and 3,4-dinitrophenyl diphenylphosphinothioate $(\mathbf{6 b})$ with alicyclic secondary amines in $80 \mathrm{~mol} \% \mathrm{H}_{2} \mathrm{O} / 20 \mathrm{~mol} \%$ DMSO at $25.0 \pm 0.1{ }^{\circ} \mathrm{C}^{a}$

\begin{tabular}{lrcc}
\hline \multirow{2}{*}{ Amines } & $\mathrm{p} K_{\mathrm{a}}$ & \multicolumn{2}{c}{$10^{3} k_{\mathrm{N}} / \mathrm{M}^{-1} \mathrm{~s}^{-1}$} \\
\cline { 3 - 4 } & & $\mathbf{6 a}$ & $\mathbf{6 b}$ \\
\hline 1. piperidine & 11.02 & 747 & 66.3 \\
2. 3-methylpiperidine & 10.80 & 729 & 70.0 \\
3. piperazine & 9.85 & 396 & 31.9 \\
4. 1-(2-hydroxyethyl)-piperazine & 9.38 & 96.4 & 10.5 \\
5. morpholine & 8.65 & 55.0 & 6.75 \\
6. 1-formylpiperazine & 7.98 & 23.8 & 3.36 \\
7. piperazinium ion & 5.95 & 2.62 & 0.654 \\
\hline
\end{tabular}

${ }^{a}$ The $\mathrm{p} K_{\mathrm{a}}$ in $20 \mathrm{~mol} \% \mathrm{DMSO}$ and $k_{\mathrm{N}}$ values for reactions of $\mathbf{6 a}$ are taken from ref. $12 \mathrm{~b}$ through a stepwise mechanism with a change in RDS, i.e., from breakdown of $\mathrm{T}^{ \pm}$for the reactions with weakly basic amines to formation of $\mathrm{T}^{ \pm}$for those with strongly basic amines (e.g., piperidine or 3-methylpiperidine). ${ }^{10}$ One might expect that the high nucleofugality of 2,4-dinitrophenoxide causes an increase in reactivity for reactions in which expulsion of the leaving group occurs at the rate-determining step (RDS) but does not influence the reactivity when the leaving group departs after the RDS. This idea is consistent with the fact that $\mathbf{3 a}, \mathbf{4 a}$ and $\mathbf{5 a}$ are less reactive than $\mathbf{3 b}, \mathbf{4 b}$ and $\mathbf{5 b}$ toward strongly basic amines although they possess a better nucleofuge. Thus, one can suggest that the nature of reaction mechanism is an important factor to govern the reactivity order.

Deduction of Reaction Mechanism. To investigate the reaction mechanism, Brønsted-type plots have been constructed for the reactions of $\mathbf{6 a}$ and $\mathbf{6 b}$. As shown in Figure 2 , the plots are linear with $\beta_{\text {nuc }}$ values of 0.52 and 0.43 for the reactions of $6 \mathbf{a}$ and $\mathbf{6 b}$, respectively. The magnitude of $\beta_{\text {nuc }}$ values has often been taken as a measure of reaction mechanism, e.g., the $\beta_{\text {nuc }}$ value decreases from $0.9 \pm 0.2$ to $0.3 \pm 0.1$ for aminolyses of esters reported previously to proceed through a stepwise mechanism with a change in RDS upon increasing amine basicity.$^{1-10}$ On the other hand, a $\beta_{\text {nuc }}$ value of $0.5 \pm 0.1$ has been reported for reactions which proceed through a concerted mechanism. ${ }^{1-10,12}$ In fact, we have concluded that the aminolysis of $\mathbf{6 a}$ proceed through a concerted mechanism on the basis of the fact that $\beta_{\text {nuc }}=$ 0.52 . $^{12 \mathrm{~b}}$

The $\beta_{\text {nuc }}$ value obtained for the reactions of $\mathbf{6 b}$ is a little smaller than that for the corresponding reactions of $\mathbf{6 a}$, but appears to be an upper limit for reactions reported previously

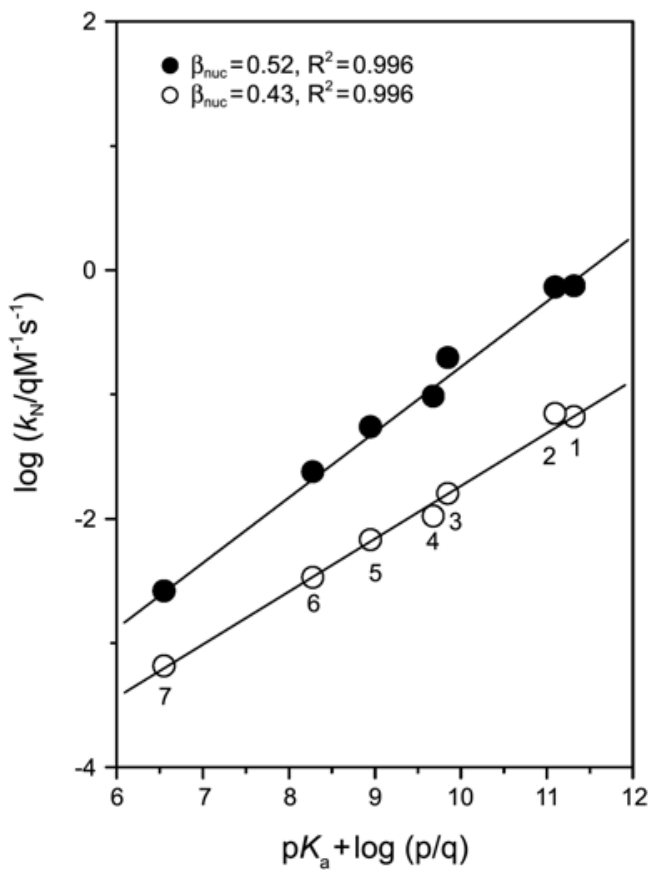

Figure 2. Brønsted-type plots for aminolysis of 2,4-dinitrophenyl diphenylphosphinothioate 6a (-) and 3,4-dinitrophenyl diphenylphosphinothioate $6 \mathbf{b}(\mathrm{O})$ in $80 \mathrm{~mol} \% \mathrm{H}_{2} \mathrm{O} / 20 \mathrm{~mol} \%$ DMSO at $25.0 \pm 0.1^{\circ} \mathrm{C}$. The identity of points is given in Table 1 . 
to proceed through a stepwise mechanism with formation of an intermediate being the RDS. Thus, one might suggest that the reactions of $\mathbf{6 b}$ proceed through a stepwise mechanism, in which leaving-group departure occurs after the RDS. This idea is consistent with the conclusion, drawn by Cook et al. from analyses of Hammett correlations, solvent effects and activation parameters, that aminolysis of aryl diphenylphosphinates in MeCN proceeds through a stepwise mechanism. ${ }^{13}$

However, we have reported that the Yukawa-Tsuno plot for the reactions of 8 different Y-substituted phenyl diphenylphosphinothioates including $\mathbf{6 b}$ with piperidine results in excellent linear correlation $\left(\mathrm{R}^{2}=0.998\right)$ with $\rho=1.91$ and $r=0.28 .^{12 \mathrm{~b}}$ Although the Yukawa-Tsuno equation was derived to account for solvolysis of benzylic system, ${ }^{14,15}$ we have shown that the equation is highly effective to elucidate ambiguities in reaction mechanism for nucleophilic substitution reactions of esters with various electrophilic centers (e.g., $\mathrm{C}=\mathrm{O}, \mathrm{C}=\mathrm{S}, \mathrm{SO}_{2}, \mathrm{P}=\mathrm{O}$ and $\left.\mathrm{P}=\mathrm{S}\right)^{16-18}$ and Michael-type additions of amines to activated acetylenes. ${ }^{19}$ It is well known that the magnitude of the $r$ value in a Yukawa-Tsuno plot represents the resonance demand of the reaction center or the extent of resonance contribution. ${ }^{14,15}$ The fact that $r=$ 0.28 for the aminolysis of aryl diphenylphosphinothioates indicates that a partial negative charge develops on the $\mathrm{O}$ atom of the leaving aryloxides in the TS. Thus, one can conclude that the aminolysis of $\mathbf{6 b}$ proceeds also through a concerted mechanism.

Plausible Reasons for Absence of Steric Hindrance. The fact that $\mathbf{6 a}$ is more reactive than $\mathbf{6 b}$ regardless of the amine basicity (Figure 2) suggests that the high nucleofugality of 2,4-dinitrophenoxide outweighs the steric hindrance which might be exerted by $2-\mathrm{NO}_{2}$ group. As discussed above, expulsion of the leaving group occurs in the TS for the reactions of $\mathbf{6 a}$ and $\mathbf{6 b}$. In this case, 2,4-dinitrophenoxide can behave as a better nucleofuge than 3,4-dinitrophenoxide since the former is $1.3 \mathrm{p} K_{\mathrm{a}}$ units less basic than the latter. However, the effect of enhanced nucleofugality on reactivity would be negligible for reactions in which expulsion of the leaving group occurs after the RDS. Thus, one can suggest that the nature of reaction mechanism is considered to be the most plausible reason why $6 \mathbf{a}$ is more reactive than $\mathbf{6 b}$.

It has generally been understood that the magnitude of $\beta_{\text {nuc }}$ values represents a relative degree of bond formation in the transition state (TS). ${ }^{1}$ The $\beta_{\text {nuc }}$ value in the current reactions of $\mathbf{6 a}$ and $\mathbf{6 b}$ are 0.52 and 0.43 , respectively, indicating that bond formation is not much advanced. Since steric hindrance would be insignificant for reactions in which bond formation between the incoming amine and the substrate is little advanced, one can suggest that the small $\beta_{\text {nuc }}$ value found for the reactions of $\mathbf{6 a}$ and $\mathbf{6 b}$ is also responsible for the fact that the steric effect exerted by 2$\mathrm{NO}_{2}$ group is less significant than the high nucleofugality.

The other plausible reason for the absence of steric hindrance in the current reactions would be the nature of the electrophilic center. The electrophilic center of $\mathbf{6 a}$ and $\mathbf{6 b}$ is tetrahedral in the ground state (GS) but it becomes trigonal bipyramidal in the TS as illustrated by $\mathrm{TS}_{\mathrm{P}=\mathrm{S}}$, in which the incoming amine and the leaving aryloxide occupy the apical positions of the trigonal bipyramidal. ${ }^{20}$ Furthermore, the $\mathrm{P}=\mathrm{S}$ bond in $\mathbf{6 a}$ and $\mathbf{6 b}$ is much larger than the $\mathrm{C}=\mathrm{O}$ bond in carboxylic esters. Thus, the $2-\mathrm{NO}_{2}$ group in the leaving group of $\mathbf{6 a}$ is too far away from the incoming nucleophile to exert steric hindrance. On the other hand, the small $\mathrm{C}=\mathrm{O}$ bond in carboxylic esters is $\mathrm{sp}^{2}$ in the GS but $\mathrm{sp}^{3}$ in the TS as illustrated by $\mathrm{TS}_{\mathrm{C}=\mathrm{O}}$. This is why the $2-\mathrm{NO}_{2}$ group of the carboxylic esters exerts strong steric hindrance on going from the GS to the TS.
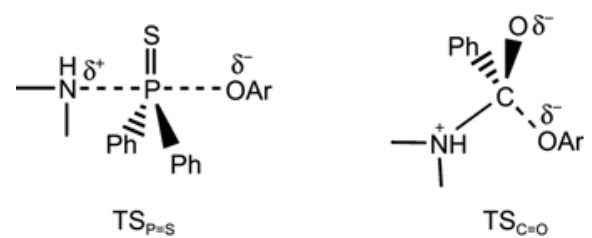

The current study has allowed us to conclude the following: (1) 2,4-Dinitrophenyl diphenylphosphinothioate $\mathbf{6 a}$ is more reactive than 3,4-dinitrophenyl diphenylphosphinothioate $\mathbf{6 b}$ regardless of the amine basicity, indicating that the high nucleofugality of 2,4-dinitrophenoxide outweighs the steric hindrance that might be exerted by $2-\mathrm{NO}_{2}$ group. (2) Aminolysis of $\mathbf{6 b}$ proceeds through a concerted mechanism with a small degree of bond formation between the incoming amine and the substrate. (3) The nature of reaction mechanism is the most important factor to govern the reactivity order, since the high nucleofugality of 2,4dinitrophenoxide would cause an increase in reactivity only for reactions in which expulsion of the leaving group occurs in the RDS. (4) The small $\beta_{\text {nuc }}$ value and the nature of the electrophilic center (i.e., the larger $\mathrm{P}=\mathrm{S}$ bond with $\mathrm{sp}^{3}$ hybridization in the GS) are also responsible for the absence of steric hindrance.

\section{Experimental Section}

Materials. 3,4-Dinitrophenyl diphenylphosphinothioate 6b was prepared by addition of 3,4-dinitrophenol to the reaction mixture of diphenylphosphinodithioic acid and $N, N^{\prime}$-dicyclohexylcarbodiimide in the presence of 4 -(dimethylamino)pyridine in methylene chloride as reported previously. ${ }^{12 \mathrm{~b}}$ The crude product was purified by column chromatography (silica gel, methylene chloride/ $n$-hexane 50/50). The purity was checked by the melting point and ${ }^{1} \mathrm{H}$ NMR spectrum. Amines and other chemicals were of the highest quality available. Doubly glass distilled water was further boiled and cooled under nitrogen just before use. Due to low solubility of $\mathbf{6 b}$ in pure water, aqueous DMSO (80 mol \% $\mathrm{H}_{2} \mathrm{O} / 20 \mathrm{~mol} \%$ DMSO) was used as the reaction medium.

Kinetics. The kinetic study was performed using a UV-vis spectrophotometer equipped with a constant temperature circulating bath. The reactions were followed by monitoring the appearance of the leaving 3,4-dinitrophenoxide. All the reactions were carried out under pseudo-first-order conditions in which amine concentrations were at least 20 times 
greater than the substrate concentration. The amine stock solution of $c a .0 .2 \mathrm{M}$ was prepared by dissolving 2 equiv of free amine and 1 equiv of standardized $\mathrm{HCl}$ solution to make a self-buffered solution in a $25.0 \mathrm{~mL}$ volumetric flask.

Products Analysis. 3,4-Dinitrophenoxide was liberated quantitatively and identified as one of the products in the reaction of $\mathbf{6} \mathbf{b}$ by comparison of the UV-vis spectra after completion of the reaction with the authentic sample under the same reaction conditions.

Acknowledgments. This work was supported by Basic Science Research Program through the National Research Foundation of Korea (NRF) funded by the Ministry of Education, Science and Technology (2009-0075488). L. R. Im and K. Akhtar are also grateful for the BK 21 Scholarship (L. R. Im) and the Predominant Foreign Student Scholarship (K. Akhtar, KRF-2007-211-C0021).

\section{References}

1. (a) Jencks, W. P.; Chem. Rev. 1985, 85, 511-527. (b) Castro, E. A.; Chem. Rev. 1999, 99, 3505-3524. (c) Page, M. I.; Williams, A. Organic and Bio-organic Mechanisms; Longman: Singapore, 1997; Chapter 7.

2. (a) Menger, F. M.; Smith, J. H. J. Am. Chem. Soc. 1972, 94, $3824-$ 3829. (b) Maude, A. B.; Williams, A. J. Chem. Soc., Perkin Trans 2 1997, 179-183.

3. (a) Castro, E. A.; Gazitua, M.; Santos, J. G. J. Phys. Org. Chem. 2010, 23, 176-180. (b) Castro, E. A.; Aliaga. M.; Campodonico, P. R.; Cepeda, M.; Contreras. R.; Santos, J. G. J. Org. Chem. 2009, 74, 9173-9179. (c) Castro, E. A.; Gazitua. M.; Santos, J. G. J. Phys. Org. Chem. 2009, 22, 1003-1008. (d) Castro, E. A. Pure Appl. Chem. 2009, 81, 685-696. (e) Castro, E. A.; Aliaga, M.; Santos, J. G. J. Phys. Org. Chem. 2008, 21, 271-278.

4. (a) Oh, H. K.; Lee, H. Bull. Korean Chem. Soc. 2010, 31, 475478. (b) Oh, H. K.; Hong, S. K. Bull. Korean Chem. Soc. 2009, 30, 2453-2456. (c) Oh, H. K.; Jeong, K. S. Bull. Korean Chem. Soc. 2009, 30, 253-256. (d) Oh, H. K.; Jeong, K. S. Bull. Korean Chem. Soc. 2008, 29, 1621-1623.

5. (a) Oh, H. K.; Ku, M. H.; Lee, H. W.; Lee, I. J. Org. Chem. 2002, 67, 8995-8998. (b) Oh, H. K.; Ku, M. H.; Lee, H. W.; Lee, I. J. Org. Chem. 2002, 67, 3874-3877. (c) Oh, H. K.; Kim, S. K.; Lee, H. W.; Lee, I. New J. Chem. 2001, 25, 313-317. (d) Oh, H. K.; Kim, S. K.; Cho, I. H.; Lee, H. W.; Lee, I. J. Chem. Soc., Perkin Trans 2 2000, 2306-2310.

6. Um, I. H.; Min, J. S.; Ahn, J. A.; Hahn, H. J. J. Org. Chem. 2000,
65, 5659-5663.

7. Castro, E. A.; Aguayo, R.; Bessolo, J.; Santos, J. G. J. Org. Chem. 2005, 70, 7788-7791.

8. Um, I. H.; Ahn, J. A.; Park, Y. M. Bull. Korean Chem. Soc. 2009, 30, 214-218.

9. (a) Gresser, M. J.; Jencks, W. P. J. Am. Chem. Soc. 1977, 99, 69636970. (b) Gresser, M. J.; Jencks, W. P. J. Am. Chem. Soc. 1977, 99, 6970-6980.

10. (a) Seo, J. A.; Lee, H. M.; Um, I. H. Bull. Korean Chem. Soc. 2008, 29, 1915-1919. (b) Um, I. H.; Akhtar, K. Bull. Korean Chem. Soc. 2008, 29, 772-776.

11. (a) Um, I. H.; Hwang, S. J.; Baek, M. H.; Kim, E. H. J. Org. Chem. 2006, 71, 9191-9197. (b) Um, I. H.; Seok, J. A.; Kim, H. T.; Bae, S. K. J. Org. Chem. 2003, 68, 7742-7746. (c) Um, I. H.; Lee, S. E.; Kwon, H. J. J. Org. Chem. 2002, 67, 8999-9005.

12. (a) Um, I. H.; Han, J. Y.; Shin, Y. H. J. Org. Chem. 2009, 74, 3073-3078. (b) Um, I. H.; Akhtar, K.; Shin, Y. H.; Han, J. Y. J. Org. Chem. 2007, 72, 3823-3829. (c) Um, I. H.; Shin, Y. H.; Han, J. Y.; Mishima, M. J. Org. Chem. 2006, 71, 7715-7720.

13. Cook, R. D.; Daouk, W. A.; Hajj, A. N.; Kurku, A.; Samaha, M.; Shayban, F.; Tanielian, O. V. Can. J. Chem. 1986, 64, 213-219.

14. (a) Tsuno, Y.; Fujio, M. Adv. Phys. Org. Chem. 1999, 32, 267-385. (b) Tsuno, Y.; Fujio, M. Chem. Soc. Rev. 1996, 25, 129-139. (c) Yukawa, Y.; Tsuno, Y. Bull. Chem. Soc. Jpn. 1959, 32, 965-970.

15. (a) Than, S.; Maeda, H.; Irie, M.; Kikukawa, K.; Mishima, M. Int J. Mass. Spect. 2007, 263, 205-214. (b) Maeda, H.; Irie, M.; Than, S.; Kikukawa, K.; Mishima, M. Bull. Chem. Soc. Jpn. 2007, 80, 195-203. (c) Fujio, M.; Alam, M. A.; Umezaki, Y.; Kikukawa, K.; Fujiyama, R.; Tsuno, Y. Bull. Chem. Soc. Jpn. 2007, 80, 23782383.

16. (a) Um, I. H.; Yoon, S.; Park, H. R.; Han, H. J. Org. Biomol. Chem. 2008, 6, 1618-1624. (b) Um, I. H.; Hwang, S. J.; Yoon, S.; Jeon, S. E.; Bae, S. K. J. Org. Chem. 2008, 73, 7671-7677. (c) Um, I. H.; Kim, E. Y.; Park, H. R.; Jeon, S. E. J. Org. Chem. 2006, $71,2302-2306$

17. (a) Um, I. H.; Hong, J. Y.; Seok, J. A. J. Org. Chem. 2005, 70, 1438-1444. (b) Um, I. H.; Chun, S. M.; Chae, O. M.; Fujio, M.; Tsuno, Y. J. Org. Chem. 2004, 69, 3166-3172.

18. (a) Um, I. H.; Im, L. R.; Kim, E. H.; Shin, J. H. Org. Biomol. Chem. 2010, 8, 3801-3806. (b) Um, I. H.; Lee, J. Y.; Ko, S. H.; Bae, S. K. J. Org. Chem. 2006, 71, 5800-5803. (c) Um, I. H.; Kim, K. H.; Park, H. R.; Fujio, M.; Tsuno, Y. J. Org. Chem. 2004, 69, 3937-3942.

19. (a) Um, I. H.; Lee, E. J.; Seok, J. A.; Kim, K. H. J. Org. Chem. 2005, 70, 7530-7536. (b) Kim, S. I.; Baek, H. W.; Um, I. H. Bull. Korean Chem. Soc. 2009, 30, 2909-2912.

20. (a) Guha, A. K.; Lee, H. W.; Lee, I. J. Org. Chem. 2000, 65, 1215. (b) Guha, A. K.; Lee, H. W.; Lee, I. J. Chem. Soc. Perkin Trans 2 1999, 765-770. 